\title{
PALAVRAS LEXICAIS E PALAVRAS GRAMATICAIS NO INGLÊS DAS CAMISETAS: PROPOSTA DE ATIVIDADE DE ANÁLISE DOS ATOS DE FALA SEGUNDO A TEORIA DE AUSTIN
}

\author{
CONTENT AND FUNCTION WORDS IN THE ENGLISH OF \\ T-SHITS: A PROPOSAL OF ANALYSIS ACTIVITY OF SPEECH \\ ACTS ACCORDING TO AUTIN'S THEORY
}

Edina Maria Araújo de VASCONCELOS ${ }^{1}$

Maria Fabiola Vasconcelos LOPES²

\begin{abstract}
Resumo: A linguagem está presente em todas as esferas da comunicação humana e tendo em vista que ela é a via pela qual as interações sociais ocorrem, nos deparamos com textos de diversos tipos propagandose em diferentes suportes, por exemplo, as frases de camisetas (MOLINETTE; CARVALHO, 2014) e a camiseta em si como, respectivamente, gênero textual e suporte, considerando-se sobretudo, o aspecto sociocomunicativo e funcional (MARCUSCHI, 2010). Em face destas observações, este artigo apresenta uma proposta para exercitar a análise linguística, a ser realizada com alunos de ensino médio. Nosso objetivo é discutir as classes de palavras, diferenciando as lexicais (ou de conteúdo) das gramaticais (ou funcionais), bem como promover a reflexão sobre a interação entre forma, uso e significados no discurso, abordando a Teoria dos Atos de Fala de Austin (1990), visando contribuir, desta forma, para o letramento em língua inglesa. A metodologia consiste em coletar e analisar as frases. Concluímos que camisetas estampadas com dizeres em inglês têm um potencial linguístico que pode ser utilizado nas aulas de língua inglesa, pois elas apresentam qualidades discursivas que, muitas vezes, vão para além do aspecto verbal, e seus textos podem ser estudados, inclusive, em suas características multimodais de linguagem.
\end{abstract}

Palavras-chave: Atos de fala. Classe de palavras. Língua inglesa

\begin{abstract}
Language is present in all spheres of human communication and considering that it is how social interactions occur, we are faced with texts of different types spreading on different supports, such as t-shirt phrases (MOLINETTE; CARVALHO, 2014) and the t-shirt itself as, respectively, textual genre and support, considering above all, the socio-communicative and functional aspect (MARCUSCHI, 2010). In light of this, this article presents a proposal to exercise a linguistic analysis, one carried out with high school students. Our goal is to discuss word classes to differentiate them into lexical (or content) or functional (grammatical), as well as to promote a reflection on an interaction between form, use, and meanings in speech, addressing Austin's Theory of Speech Acts (1990), thus contributes to English literacy. The methodology consists of collecting and analyzing the sentences. We conclude that T-shirts printed with English sayings have a linguistic potential that can be used in English language classes, as they present discursive features that often go beyond the verbal facet, and their texts can be studied, including their multimodal language characteristics.
\end{abstract}

Keywords: Acts of speech; Class of words; English language.

\footnotetext{
1 Universidade Federal do Ceará (UFC), Ceará, Fortaleza, Brasil; edina.araujo.vasconcelos@hotmail.com; https://orcid.org/0000-0002-9247-1146
}

2 Universidade Federal do Ceará (UFC), Ceará, Fortaleza, Brasil; fbiolloes.ufc@gmail.com;

https://orcid.org/0000-0002-1689-549X 
- Palavras lexicais e palavras gramaticais no inglês das camisetas: proposta de atividade de análise dos atos de fala segundo a teoria de Austin

\section{Introdução}

A linguagem está presente em todas as esferas da comunicação humana; em um mundo no qual as interações sociais ocorrem via linguagem (verbal, não-verbal, verbovisual, etc.), nos deparamos com textos de diversos tipos propagando-se em diferentes suportes. Neste sentido, destacamos as frases de camisetas (MOLINETTE; CARVALHO, 2014) e a camiseta em si como, respectivamente, gênero textual e suporte. A princípio, esta peça do vestuário foi, como qualquer outra roupa, criada por motivo de "pudor, proteção [ou] adorno" (STEFANI, 2005, p. 15), mas posteriormente, ampliou a sua função de vestir o corpo para se tornar um veículo de expressão de comunicação "por meio da grande quantidade de mensagens e composições verbo-visuais estampadas na superfície têxtil" (CALZA, 2009, p. 13). Desde a década de 1960, esta peça do vestuário se transformou em uma forma universal, unissex e democrática para proclamar ou enviar mensagens e compartilhar diferentes sentidos (CALZA, 2009; MAIA; GOMES, 2007).

Em face destas observações, este artigo apresenta uma proposta para exercitar a análise linguística, fruto de atividade pedagógica, a ser realizada com alunos de ensino médio. A atividade tem como objetivo discutir as classes de palavras, diferenciando as lexicais (ou de conteúdo) das gramaticais (ou funcionais) ${ }^{3}$, bem como promover a reflexão sobre a interação entre forma, uso e significados no discurso, abordando a Teoria dos Atos de Fala de Austin (1990), visando contribuir, desta forma, para o letramento em língua inglesa.

\section{Referencial teórico}

Do ponto de vista do funcionalismo linguístico, que traz para o cerne da questão o interesse em estudar a relação entre estrutura gramatical e os diferentes contextos comunicativos em que elas ocorrem, a língua é um instrumento de interação social e o contexto em que ela é usada é o que motiva as diversas estruturas sintáticas.

A pragmática linguística também advoga a esse favor, quando propõe o "deslocamento considerável do ponto de vista do sistema para a atividade comunicativa" (MARCUSCHI, 2008, p. 37). Não se trata de excluir ou ignorar a forma, pois ela constitui o sistema linguístico e, sem ela, pode-se dizer que não há como definir parâmetros mínimos

3. A discussão acerca da categorização das palavras é ampla e não é possível tratá-la de forma eficiente neste trabalho; ressaltamos que a distinção que apresentamos aqui baseia-se em diferentes leituras, por exemplo, Nascimento e Carvalho (2012), Cavalcanti (2004), Azeredo (2013), Santana (2013) e Trask (2011), todos referenciados nesta obra. 
para o ensino de língua, especialmente a estrangeira; no entanto, é de fundamental importância que se leve em conta os significados que as formas linguísticas obtêm quando considerados os seus usos em função da atividade comunicativa às quais elas se propõem realizar.

É no âmbito da discussão sobre forma que apresentamos uma breve definição entre palavra lexical e palavra gramatical, proposta por Cavalcanti (2004). O autor afirma que "existem dois tipos básicos de palavras: aquelas que se referem a objetos e a eventos do mundo real (ou de nossa imaginação) e outras que só existem para o funcionamento da língua" (CAVALCANTI, n.p.); as primeiras são as lexicais e as segundas, as gramaticais. Em se tratando de língua portuguesa, Cavalcanti (2004) afirma que o grupo de palavras lexicais compreende os nomes e verbos, ao passo que o de palavras gramaticais é composto de pronomes, artigos e conectivos (conjunções e preposições); ele admite as dez classes de palavras apresentadas pela gramática (Substantivo, Artigo, Adjetivo, Pronome, Numeral, Verbo, Advérbio, Preposição, Conjunção e Interjeição), mas afirma que há critérios semânticos e funcionais para estabelecer o seguinte quadro:

Quadro 1. Palavra lexical e palavra gramatical

\begin{tabular}{||l||l|l||}
\hline & critério semântico & critério funcional \\
\hline \hline $\begin{array}{l}\text { palavras lexicais } \\
\text { (inventário aberto) }\end{array}$ & $\begin{array}{l}\text { Nome (inclusive } \\
\text { Numeral) }\end{array}$ & substantivo \\
\hline \hline & & adjetivo \\
\hline \hline & Verbo & advérbio \\
\hline \hline $\begin{array}{l}\text { palavras gramaticais } \\
\text { (inventário fechado) }\end{array}$ & $\begin{array}{l}\text { Pronome (inclusive } \\
\text { grtigo) "nome }\end{array}$ & substantivo \\
\hline \hline & & adjetivo \\
\hline \hline & Conectivo & advérbio \\
\hline \hline & & coordenativo \\
\hline \hline
\end{tabular}

Fonte: Cavalcanti (2004)

Seguindo a divisão em classes de palavras, Nascimento e Carvalho (2012, p. 1) afirmam que, em se tratando de língua inglesa, as palavras podem ser dispostas em duas classes: 
- Palavras lexicais e palavras gramaticais no inglês das camisetas: proposta de atividade de análise dos atos de fala segundo a teoria de Austin

Content Words e Function Words. As Content Words, que chamaremos [...] de palavras de conteúdo, são aquelas que possuem carga semântica, enquanto Function Words, [...] palavras funcionais, são aquelas que servem apenas para expressar a relação gramatical necessária entre as palavras com carga semântica.

Os autores também propõem um quadro apresentando as categorias divididas em palavras de conteúdo e palavras funcionais:

Quadro 2. Palavra de conteúdo e palavra funcional

\begin{tabular}{|l|l|}
\hline \multicolumn{1}{|c|}{ Palavras de Conteúdo } & \multicolumn{1}{c|}{ Palavras Funcionais } \\
\hline Substantivos & Artigos \\
Verbos Principais & Verbos Auxiliares \\
Adjetivos & Pronomes Pessoais \\
Pronomes possessivos & Adjetivos Possessivos \\
Pronomes demonstrativos & Adjetivos Demonstrativos \\
Pronomes Interrogativos & Preposições \\
Partículas Negativas/ Contrações & Conjunções \\
Advérbios / Locuções Adverbiais & \\
\hline
\end{tabular}

Fonte: Celce-Murcia, Brinton e Goodwin (1996 apud NASCIMENTO; CARVALHO, 2012, p. 2)

Diferentemente do quadro proposto por Cavalcanti (2004), a classificação apresentada por Nascimento e Carvalho (2012) se ajusta aos propósitos deste artigo, visto que esta dispõe sobre a língua inglesa. Para completar o arcabouço teórico proposto neste texto, passamos a falar da Teoria dos Atos de Fala, proposta pelo filósofo da linguagem britânico John Austin, que se insere no campo da pragmática, esta disciplina "jovem, farta, de fronteiras fluídas, [oriunda do] cruzamento das pesquisas em filosofia e em linguística" (ARMENGAUD, 2006, p. 9).

De acordo com Austin (1990), a linguagem é uma forma de realizar ações, e não meramente de descrição do mundo. Para o autor, a concepção de linguagem envolve os elementos do contexto, bem como as convenções de uso e as intenções dos falantes; seus postulados preconizam que "a linguagem deve ser tratada essencialmente como uma forma de ação, e não de representação da realidade". Em outras palavras, ele defende que é por meio da linguagem que não apenas descrevemos o mundo, mas também atuamos linguisticamente nele, de forma a praticarmos ações, como ordenar, convidar, denunciar, etc. 
Na teoria de Austin, concebida em um tempo em que muitos filósofos e gramáticos acreditavam que a linguagem servia apenas para descrever o estado de coisas, o autor lança mão de enunciados, de primeira pessoa do singular, do presente do indicativo da voz ativa, que não descrevem nada, e põe em discussão a "ilusão descritiva" acerca da linguagem (FIORIN, 2014, p. 170). Numa delimitação preliminar, ele categoriza os enunciados em contatativos e performativos, estabelecendo que os primeiros descrevem estados de coisas, como na frase "O céu é azul"; enquanto os segundos realizam ações, como na frase "Eu declaro aberta a seção".

Austin também apresenta uma tipologia das condições de felicidade dos performativos, que são as situações necessárias para que um performativo seja bemsucedido quando executado na linguagem; segundo ele, é necessário que o procedimento especificado e seu efeito sejam convencionados na comunidade, e sua execução ocorra de forma correta e completa; a última condição diz respeito à forma como o falante e seus interlocutores se conduzem no procedimento, ou seja, é necessária uma convergência de sentimentos e intenções por parte dos interlocutores e a conduta dos participantes deve ser conforme esses acordos (cf. AUSTIN, 1990). Tome-se, como exemplo, o caso de uma aposta, que ocorre apenas quando falante e ouvinte concordam nesse propósito. A não-observância das condições de felicidade incorrem naquilo que o autor denomina violações, que podem ser falhas ou abusos (cf. LEVINSON, 2007).

Com a evolução interna da teoria, já que é o próprio Austin que, ao tentar definir os atos de fala, acaba refutando uma a uma as suas definições, para finalmente concluir que tudo é ato de fala. O autor, então, apresenta o que chama de Teoria Geral dos Atos de Fala, e demonstra a pluridimensionalidade de atos praticados na linguagem, descrita brevemente a seguir:

- Ato Locucionário: é o próprio conteúdo linguístico usado para dizer algo (cf. WILSON, 2011), ou seja, trata-se da "totalidade da ação linguística" (OLIVEIRA, 2006, p. 158) em sua dimensão fonética, sintática e de referência;

- Ato Ilocucionário: se realiza na linguagem e, através da Força Ilocucionária, realiza as funções de pedir, informar, elogiar, entre outras; segundo Wilson (2011, p. 93), "corresponde ao ato efetuado ao se dizer algo";

- Ato Perlocucionário: este ato pretende, por meio das expressões linguísticas, provocar efeitos nos sentimentos, pensamentos, e ações do outro (convencer, levar a uma decisão, etc.).

Na tentativa de classificar os atos ilocucionários, Austin procede com a seguinte categorização: (AUSTIN, 1962, apud ARMENGAUD, 2006, p. 103-104): 
- Palavras lexicais e palavras gramaticais no inglês das camisetas: proposta de atividade de análise dos atos de fala segundo a teoria de Austin

- Os veridictivos: eles consistem em pronunciar um julgamento (veredicto) fundado na evidência ou em boas razões, acerca de um valor ou de um fato. Exemplos: desculpar, considerar, calcular, descrever, analisar, estimar, classificar, avaliar, caracterizar.

- Os exercitivos: eles consistem em formular uma decisão em favor ou no sentido de uma sequência de ações. Exemplos: ordenar, comandar, defender, suplicar, recomendar, implorar, aconselhar. Assim como: nomear, declarar uma seção aberta, fechada, advertir, proclamar.

- Os comissivos: eles comprometem o leitor com determinadas sequências de ações. Exemplo: prometer, fazer voto (de), comprometer-se por contrato, garantir, jurar, adotar uma convenção, aderir a um partido.

- Os expositivos: eles são utilizados para expressar concepções, conduzir uma argumentação, esclarecer a utilização de palavras, assegurar as referências. Exemplos: afirmar, negar, responder, objetar, conceder, exemplificar, parafrasear, relacionar metas.

- Os comportamentais: trata-se de reações ao comportamento dos outros, aos acontecimentos que lhes dizem respeito; são expressões de atitudes acerca de seu comportamento ou de seu destino. Exemplos: desculpar-se, agradecer, felicitar, desejar boas-vindas, criticar, exprimir condolências, abençoar, amaldiçoar, fazer um brinde, beber à saúde. E ainda: protestar, provocar, desafiar.

\section{Metodologia}

O corpus da atividade constitui-se de textos escritos em língua inglesa presentes nas camisetas, os quais podem ser coletados pelos próprios alunos, nos moldes do trabalho de Molinette e Carvalho (2014) e Calza (2009). A partir da escolha dos textos, pode-se proceder a análise, classificando as palavras dos enunciados, separando-as em classes gramaticais, e identificando-as enquanto palavra lexical e palavra funcional.

Esta etapa do processo põe em prática conhecimentos formais (sintaxe e morfologia), mas é necessário abarcar também o semântico e o pragmático, o que, numa análise baseada no funcionalismo linguístico, é de suma importância para a compreensão do texto. Ao aplicar esta atividade, pode-se sugerir a consulta a dicionários, para que os alunos pensem em quais contextos seriam ditas as frases estudadas, na tentativa de 
esclarecer que a produção do sentido está relacionada ao seu uso efetivo, como apregoa Marcuschi (2008, p. 37): “o sentido se torna algo situado, negociado, produzido fruto de efeitos enunciativos e não algo prévio, imanente e apenas identificável como um conteúdo".

\section{Análise e discussão}

Através do vestuário, também percebemos a possibilidade de "diferentes construções discursivas que atualizam ou revelam dados e posições sobre o sujeito [...] impondo assim uma prática e um exercício de linguagem" (CALZA, p. 2, grifo nosso). Em busca destas construções discursivas, apresentamos no quadro 3 exemplares de textos coletados em camisetas, os quais analisamos a seguir:

Quadro 3: Textos coletados em camisetas

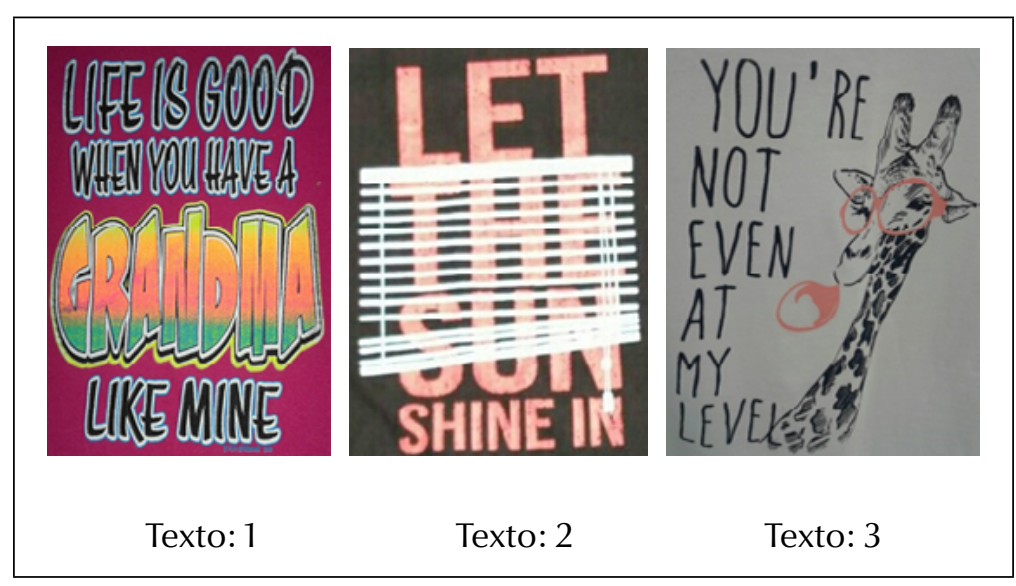

Fonte: Elaborado pela autora

A primeira atividade diz respeito ao reconhecimento das palavras de cada texto e à categorização das mesmas enquanto partes do discurso ${ }^{4}$. Segundo as definições apresentadas por Trask (2011, p. 218), trabalhamos com a definição de palavra morfossintática, que diz respeito a "qualquer uma das formas que um item lexical pode assumir para fins gramaticais". Azeredo (2013, p. 43) também nos chama a atenção para um aspecto fundamental das palavras: " a relação entre a forma que a apresentam e a utilidade e função que tem".

4 Trask (2011, p. 218) afirma que "há pelo menos quatro maneiras de definir a palavra"; ele considera a ortográfica, a fonológica, o item lexical ou lexema e a morfossintática. O mesmo autor menciona também o fato de elas estarem agrupadas em pequenos números de classes, que já foram denominadas partes do discurso, classes de palavras, categorias lexicais. 
- Palavras lexicais e palavras gramaticais no inglês das camisetas: proposta de atividade de análise dos atos de fala segundo a teoria de Austin

Considerando o fato de serem as palavras lexicais portadoras de conteúdo nocional específico, observamos que os textos apresentam os seguintes exemplos:

Quadro 4. Palavras lexicais

\begin{tabular}{|c|c|c|c|}
\hline VERBO & SUBSTANTIVO & ADJETIVO & ADVÉRBIO \\
\hline be (is/are); have; let; shine & life; grandma; sun; level & good & even \\
\hline
\end{tabular}

Fonte: Elaborado pela autora

Quanto às palavras gramaticais, aquelas que não têm associação a fatos, fenômenos ou processos, e cujo sentido depende das combinações em que se encontram nas orações, podemos identificar:

Quadro 2. Palavras gramaticais

\begin{tabular}{|c|c|c|c|c|c|c|}
\hline CONJUNÇÃO & \multicolumn{2}{|c|}{ ARTIGO } & \multicolumn{3}{c|}{ PRONOME } & PREPOSIÇÃO \\
\hline \multirow{2}{*}{ when } & Definido & Indefinido & Pessoal & $\begin{array}{c}\text { Possessivo } \\
\text { Adjetivo }\end{array}$ & Possessivo & \multirow{2}{*}{ in; like*; at } \\
\cline { 2 - 6 } & the & a & you & my & mine & \\
\hline
\end{tabular}

Fonte: Elaborado pela autora

Algumas observações são pertinentes nesta classificação, pois sabemos que incluir uma palavra em uma classe deve obedecer a critérios. É o caso de *like, que está relacionada na categoria preposição e, em seu sentido prototípico, é um verbo. Isto ocorre porque, nesse exemplo específico, devemos considerar uma particularidade "a inclusão de uma palavra nesta ou naquela classe é melhor determinada por critérios gramaticais", ou seja, critérios funcionais nos enunciados. No texto em questão (texto 1), a palavra like funciona como preposição; observe que ela ocorre no mesmo paradigma de $\underline{\text { as }}$ mine ou in the same manner as mine.

Em termos de sintaxe, o texto 1 corresponde a um período composto por subordinação e trata-se de uma declaração; ele afirma que a vida é boa quando se tem uma avó feito a do falante. Sob o ponto de vista pragmático, decorre a ideia compartilhada social e culturalmente de que avós em geral mantêm boas relações com seus netos, muitas vezes são afetuosas e carismáticas. O que o texto nos diz é que as avós são boas e isso torna a vida boa também.

Segundo a teoria de Austin, o ato ilocucionário realizado cumpre a função de elogiar, uma vez que, mesmo de forma indireta, o falante faz um julgamento acerca do fato de viver baseado em uma situação familiar. De fato, o proferimento elogia as avós; portanto, observamos no texto 1 um ato ilocucionário veridictivo. 
O texto 2 constitui-se de um período simples, mas com status informacional bastante relevante: apresenta um verbo no modo imperativo. Sabemos que esse modo específico pode ser utilizado para expressar uma ordem ou instrução, sugestão ou oferecimento e até um desejo.

É o contexto pragmático que vai diferenciar o emprego de cada uma dessas funções discursivas, mas podemos dizer que o enunciado em questão realiza um ato ilocucionário exercitivo, uma vez que formula uma decisão para a qual se espera uma sequência de ações, no caso, de permitir que o sol adentre um ambiente, pois depreendemos da imagem, que apresenta uma persiana entreaberta, que deve ocorrer esse movimento.

Observamos também no texto 2 a deonticidade presente na estrutura verbal utilizado pelo falante. $\mathrm{O}$ verbo no imperativo pode expressar também uma imposição ou sugestão, e isto vai depender dos envolvidos no ato comunicativo e do conhecimento pragmático que o falante tem a respeito do ouvinte. As relações entre estes balizam o valor deôntico do enunciado.

Assim como o texto 2, o texto 3 também apresenta um período simples, mas contém um verbo negativo. Segundo Givón (2012, p. 126), a diferença entre as afirmativas e as suas correspondentes negativas não está somente no valor de verdade expresso por cada uma delas, mas ocorre de fato um "elemento adicional", denominado pressuposição discursiva.

Para o autor, quando o falante faz a escolha por enunciar uma sentença negativa, ele supõe ainda mais sobre o conhecimento do seu ouvinte do que quando profere enunciados afirmativos. De acordo com essa observação, o operador da negação pode afetar diferentes conteúdos na sentença (um termo, o predicado, a proposição ou o próprio ato ilocucionário).

No texto analisado, o escopo da negação incide sobre a proposição inteira e é reforçado pelo uso da partícula even, denotando que é compartilhado entre falante e ouvinte a informação que este supostamente não se enquadra sequer em um nível de comparação com aquele.

No que diz respeito ao ato de fala, o texto 3 realiza um performativo comportamental, pois expressa uma reação ao comportamento de outrem, deixando clara a crítica e a provocação ao interlocutor. 
- Palavras lexicais e palavras gramaticais no inglês das camisetas: proposta de atividade de análise dos atos de fala segundo a teoria de Austin

\section{Considerações finais}

No contexto de ensino-aprendizagem da linguagem, é um fato importante que as camisetas veiculam diferentes gêneros textuais, tais como, propaganda, poesia, letra de música e as chamadas citações ou frases de efeito, as quais podem ter sua autoria identificada ou não, e podem ser de incentivo, de protesto, entre outros. Tais textos podem ser usados na disciplina de língua inglesa, como propõem Molinete e Carvalho (2014).

A camiseta é, por assim dizer, um suporte textual diferenciado, dada a sua extrema popularidade (cf. CARSTENS, 2010, p. 196), pois são tidas "como peças fundamentais nos armários"; segundo a autora, elas podem ser até "consideradas pequenos outdoors que os indivíduos utilizam e que funcionam como ícones de suas posturas, ideais e conceitos". A motivação para o que podemos chamar de "sucesso editorial das T-shirts" remonta à sua trajetória, que passou de roupa sem grande importância na década de 1930, usada por operários e, posteriormente, por militares, até chegar ao glamour do cinema na década de 1950; já na década seguinte, ela seria usada com motivações políticas e de protesto (especialmente pelo movimento hippie) e nos anos de 1970, utilizadas pelo movimento punk, com seus slogans cheios de ironia e provocação; as camisetas desembarcam na década de 1980 abraçadas pelas grandes grifes, que consolidam de vez a sua popularidade a partir de 1990 (CARSTENS, 2010).

Dada a sua popularidade e seu potencial para difundir textos, é comum nos depararmos com enunciados em inglês circulando em nossa sociedade através de camisetas, ainda que alguns de seus usuários pareçam sequer atentar ou compreender $\mathrm{o}$ que realmente está escrito nelas. Com base no que foi exposto até aqui, nossa hipótese é que as camisetas estampadas com dizeres em inglês têm um potencial linguístico que pode ser utilizado nas aulas de língua inglesa, pois elas apresentam qualidades discursivas que, muitas vezes, vão para além do aspecto verbal, e seus textos podem ser estudados inclusive, em suas características multimodais de linguagem. Ademais, seguimos a premissa de Calza (2009, p. 140, grifos do autor) o qual afirma que camisetas "comunicam interpelando, incitando ou provocando os sujeitos-leitores - tanto por meio das frases feitas e objetivas, das perguntas e interlocuções propostas, através das imagens e cores, dos grafismos e símbolos estampados [...]", problematizando questões atreladas a seus "aspectos linguístico-discursivos" (MAIA; GOMES, 2007), tão propícios ao ensino de língua em geral.

Estudar a linguagem do ponto de vista dos atos que realizamos nos oferece a oportunidade de refletir sobre o processo de reinventar significados e explorar o conteúdo 
linguístico para além da forma, pontuando inclusive que a linguagem é forma de agir no mundo, e não somente de descrevê-lo. Segundo Martinez (2009, p. 9-10), o aprendiz de uma língua estrangeira deve se apropriar, no decorrer do seu processo de aprendizagem, de elementos novos, dentre os quais devem estar os saberes linguísticos (léxico, elementos e as regras de funcionamento da língua) e as competências comunicativas, ou seja, "as habilidades, meios para agir sobre o real (maneiras de ordenar, de aprovar, de se apresentar, de informar)".

\section{REFERÊNCIAS}

AZEREDO, J. C. de. Gramática Houaiss da língua portuguesa. São Paulo: Publifolha, 2013.

ARMENGAUD, F. Tradução Marcos Marcionilo. A pragmática. São Paulo: Parábola Editorial, 2006.

AUSTIN, J. L. Quando dizer é fazer: palavras em ação. Tradução Danilo Marcondes de Sousa Filho. Porto Alegre: Artes Médicas, 1990.

CALZA, M. U. A camiseta e a rua: processos interacionais entre sujeitos pelo vestir. 2009. Dissertação (Mestrado em Ciências da Comunicação) - Universidade do Vale do Rio dos Sinos, Rio Grande do Sul, 2009. Disponível em: https://bit.ly/2VWSN76. Acesso em: 06 out. 2020.

CARSTENS, L. R. Camisetas: outdoors ambulantes. Estudos em Comunicação, v. 2, n. 7, p. 195-211, maio 2010. Disponível em: http://www.ec.ubi.pt/ec/07/vol2/carstens.pdf. Acesso em: 06 out. 2020.

CAVALCANTI, C. B. O. Moderna perspectiva das classes de palavras. In: CONGRESSO NACIONAL DE LINGUÍSTICA E FILOLOGIA, 8., 2004, Rio de Janeiro. Anais eletrônicos... Rio de Janeiro: Instituto de Letras da Universidade do Estado do Rio de Janeiro, 2004. Disponível em: http://www.filologia.org.br/viiicnlf/anais/caderno03-15.html. Acesso em: 15 out. 2020.

FIORIN, J. L. A linguagem em uso. In: FIORIN, J. L. (org.). Introdução à linguística: objetos teóricos. São Paulo: Contexto, 2014. 
- Palavras lexicais e palavras gramaticais no inglês das camisetas: proposta de atividade de análise dos atos de fala segundo a teoria de Austin

GIVÓN, T. A compreensão da gramática. Tradução Maria Aparecida Furtado da Cunha, Mario Eduardo Martelotta e Filipe Albani. São Paulo: Cortez Editora, 2012. Cap. 3, p. 125-190.

LEVINSON, S. C. Pragmática. Tradução Luís Carlos Borges e Aníbal Mari. São Paulo: Martins Fontes, 2007. Cap. 5, p. 287-360.

MAIA, D. G.; GOMES, M. C. A. De peça de roupa para gênero discursivo: uma descrição do gênero camisa de formatura do ensino médio. Revista de Ciências Humanas, Minas gerais, v. 7, n. 1, p. 85-98, jan./jun. 2007. Disponível em: https://periodicos.ufv.br/RCH/ article/view/3553. Acesso em: 06 out 2020.

MARCUSCHI, L. A. Gêneros textuais: definição e funcionalidade. In: DIONÍSIO, Â. P.; MACHADO, A. R.; BEZERRA, M. A. (org.). Gêneros textuais e ensino. São Paulo: Parábola Editorial, 2010. Cap. 1, p. 19-38.

MARCUSCHI, L. A. Produção textual, análise de gêneros e compreensão. São Paulo: Parábola Editorial, 2008.

MARTINEZ, P. Didática de línguas estrangeiras. São Paulo: Parábola Editorial, 2009.

MOLINETTE, A. M. B.; CARVALHO, R. C. M. What wave takes us? Repensando as construções discursivas em língua estrangeira no mundo em que vivemos. In: PARANÁ, Seduc: os desafios da escola pública paranaense na perspectiva do professor PDE. 2014.

NASCIMENTO, K. R. S. do; CARVALHO, W. J. de A. Palavras funcionais do inglês: características formânticas e de duração na produção de estudantes brasileiros de ILE. In: JORNADA NACIONAL DO GRUPO DE ESTUDOS LINGUÍSTICOS DO NORDESTE, 24., 2012, Rio Grande do Norte. Anais eletrônicos... Universidade Federal do Rio Grande do Norte, 2012. Disponível em: https://bit.ly/335WGe4. Acesso em: 15 out. 2020.

OLIVEIRA, M. A. de. Reviravolta linguístico-pragmática na filosofia contemporânea. 3. ed. São Paulo: Edições Loyola, 1996. Parte II, cap. 2.

SANTANA, B. P. Morfologia e léxico atacam as palavras. Estudos linguísticos e literários, Revista dos programas de pós-graduação em língua e cultura e literatura e cultura da UFBA, Salvador, n. 48, p. 130-148, jul./dez. 2013. Disponível em: https://portalseer.ufba. br/index.php/estudos/article/view/14539. Acesso em: 15 out. 2020. 
STEFANI, P. da S. Moda e comunicação: a indumentária como forma de expressão. 2005. Monografia (Graduação em Comunicação Social) - Faculdade de Comunicação Social, Universidade Federal de Juiz de Fora, Juiz de Fora, 2005. Disponível em: https://www. ufff.br/facom/files/2013/04/PSilva.pdf. Acesso em: 06 out. 2020.

TRASK, R. L. Dicionário de linguagem e linguística. Tradução Rodolfo Ilari. São Paulo: Contexto, 2011.

WILSON. V. Motivações pragmáticas. In: MARTELOTTA, M. E. (org.). Manual de linguística. São Paulo: Contexto, 2011. Cap. 6, p. 87-110.

COMO CITAR ESTE ARTIGO: VASCONCELOS, Edina Maria Araújo de; LOPES, Maria Fabiola Vasconcelos. Palavras lexicais e palavras gramaticais no inglês das camisetas: proposta de atividade de análise dos atos de fala segundo a teoria de Austin. Revista do GEL, v. 17, n. 3, p. 329-341, 2020. Disponível em: https://revistadogel.gel.org.br/ DOI: http://dx.doi.org/10.21165/gel.v17i3.2706

Submetido em: 30/09/2019 | Aceito em: 17/10/2020. 